\title{
Regulatory competence as a factor of semantic co-directed interaction of teachers and students of master's degree
}

\author{
Vladimir Sokhranov-Preobrazhensky \\ Of the "Penza state University", Russia.
}

\begin{abstract}
: the urgency of consideration of the semantic interaction of teachers and students through the development of their readiness for samoregulyatsiya competent regulatory support individual trajectory of professional and didactic actions on the basis of the integrative personal characteristics; the process of implementation of the program of interactive development of regulatory competence as a factor of semantic co-directed interaction of teachers and students of the master's degree of the University in the course of teaching the discipline "Acmeological foundations of identity and meaning formation"is considered. Data on the results obtained and criteria for effective evaluation of the results of the process under study are presented. The substantiation of the concept of "educational semantic Elevator" implemented by students as a trajectory of individual and personal self-development in the conditions of psychological and pedagogical support from teachers and psychologists is presented;.semantic conditionality of development of regulatory competence in professionally directed didactic interaction of teachers and students of faculties of pedagogy and psychology in the course of studying of disciplines of a psychological and pedagogical cycle; qualitative characteristics of the co-directed semantic professionally significant didactic interaction.Abstract: the article deals with the process of implementation of the program of interactive development of regulatory competence as a factor of semantic co-directional interaction of teachers and students of the master's degree in the course of teaching the discipline "acmeological basis of identification and meaning formation". Provides information about the results obtained and the criteria for an effective evaluation of the results of the process under study. The substantiation of semantic conditionality of development of regulatory competence in professionally directed didactic interaction of teachers and students of faculties of pedagogy and psychology in the process of studying disciplines of psychological and pedagogical cycle is presented.
\end{abstract}

Introduction. The modern system of higher education in Russia makes the transition from the verbal-activity paradigm of professional training to a multi-level model of support for the development of self-organizational readiness of future bachelors, masters and graduate students to the chosen type of professional activity. In this process contradictions between innovative normative and legal bases of development of domestic education and absence of actual readiness of teachers to realization of cognitive-semantic interaction with students are obviously shown.

The presence of this situation is interrelated with a number of circumstances identified in the course of a long-term study conducted on the basis of the faculties of pedagogy and psychology of pedagogical universities of the Volga region. These, in particular, include: didactic position formed in the process of professional training of the twentieth century; long-term experience of successful professional self-realization in the paradigm of knowledge training of specialists in higher education; implementation of the reproductive level of the set of professional actions, the purpose of which is determined by the mechanism of didactic influence on students; lack of skills and competencies of selfregulation, leading to the inability to identify academic education with the content of practical professional activities of future bachelors and masters.

The removal of the considered problematic moments in the professional training of University students is based on the semantic system and activity organization of didactic interaction in the context of psychological and pedagogical support for the development of regulatory competence of future teachers-psychologists in the process of studying the disciplines of the psychological and pedagogical cycle.

To solve this problem, in the structure of curricula for GEF 3, GEF - 3+ and GEF-3++ introduced the subject " Acmeological foundations of identification and search for meaning."

The purpose of the discipline "Acmeological foundations of identity and meaning formation" is psychological and pedagogical support of the development of competence of future masters in the processes of professional identification and meaning formation in the context of the formation of regulatory competence. The goal was achieved by solving the following tasks:

- to study the basic concepts of meaning-forming acmeological professional identification; 
- to consider technologies of semantic system and activity organization of didactic interaction in the context of psychological and pedagogical support of development of regulatory competence of future teachers-psychologists;

- to identify the features of training of different social groups, for which the sense-forming acmeological identification can become a factor of personally significant professional self-organization;

- to study the main methods of development of regulatory competence readiness for meaning-forming acmeological professional identification.

Methods and techniques. Monitoring of readiness of students for semantic acmeological identification with the chosen image of professional activity, entering the magistracy, was carried out on the basis of implementation of methods of situational and problem modeling and techniques: "Value questionnaire" sh. Schwartz; test of life orientations D. A. Leontiev (szho), questionnaire for measuring motivation of achievement A. Mehrabian, method of professional self-determination Golland, questionnaire to identify readiness to choose a profession V. B. Uspensky, questionnaire "Style of self-regulation of behavior" V. I. Morosanova, D. Amirkhan's method "Indicator of coping strategies". [7,8,9,10]

Results and discussions. The obtained results allow to state the statement about insufficient readiness of students to development of regulatory competence on the basis of semantic co-directed interaction of teachers and students. To show self-regulating bases in realization of abilities to set professionally significant concrete didactic purposes (37,9\% of cases, from number of the recorded); to correlate the received didactic results of educational activity with possible future results of professional activity (14,6\% - do not go beyond the didactic understanding of the results of educational activity; 25,6\% - seek to implement a model of professional behavior at the level of imitation of the algorithm obtained in the course of classes; $36,9 \%$ - seek only to obtain a didactic positive certification and only $22,9 \%$ of students have a regulatory basis for competent correlation of didactic and professional results).

Based on the results of the monitoring in the process of studying the course "Acmeological basics of identification and search of meaning", implemented a program of psychological and pedagogical support of the development of regulatory competence in the context of the development of semantic co-directional interaction of teachers and graduate students. Differences in the meanings of professional self-realization of teachers and didactic self-realization of students were taken into account. Teachers and students in the process of interaction realized social, vital and ideal semantic installations.

As is known, motivation actualizes the implementation of the semantic basis of interaction and determines the measure of awareness of the personal meaning of the development of regulatory competence of the individual.

In the process of monitoring, before the implementation of the developed model of studying the developed training course, the readiness of teachers and students to implement the following semantic positions in the process of interaction was revealed:

- vital meanings:

a) life for the sake of life: teachers and students realizing this kind of meaning avoid destructive conflictology in communication; they manifest the principle of "live here, today and now" and the desire to realize the prospects of " near action»;

b) $6.3 \%$ of students and $2.5 \%$ of teachers interact on the basis of gender-sexual pleasure. Falling in love allows them to make sense of social self-sufficiency and, basically, it is not related to the professional basis of regulatory competence.

A certain part of teachers and students interact and strive to achieve professional and educational results on the basis of ideal semantic identification. They co directionally realize the following types of ideal meanings:

a) their interaction reveals the desire of teachers and students to realize the meaning of "life for the sake of knowledge", in this case, professional and educational activities are the basis for the development of professionally significant regulatory competence based on the desire to obtain new personal experience of performing professional and educational actions; 
b) a certain part of teachers and students (56,3\% and 34,2\% respectively), who have creative thinking, included in the implementation of the concept of interactive professionally significant development of regulatory competence, realize in interaction the semantic foundations of activity for the sake of creativity, which they realize as a necessary component of self-organization;

C) $36.7 \%$ of teachers and $37.8 \%$ of students consider the possibility of developing regulatory competence based on the sense of self-improvement. They determine the meaning of their interaction based on the long-range perspective.

In recent years, the development process in higher education actualizes the implementation of the social meaning of the development of regulatory competence on the basis of the desire to achieve professional excellence and build both vertical and horizontal careers.

The U-Mann-Whitney criterion was used to carry out mathematical and statistical data processing on the readiness of University students to the meaning-forming professional readiness to implement a set of socially significant meanings, which allows to determine the differences between the two data series:

- significant differences between the presence of goals in the lives of students of experimental and control groups Uemp $=330$ at the level of significance of $5 \%$ were revealed .

- significant differences between the use of such a strategy as avoiding problems and solving problems of students of experimental and control groups Uemp $=276$ and Uemp $=280$ at the level of significance 1 were revealed $\%$;

- insignificant differences between the value profiles of both normative and personal priorities of students of experimental and control groups Uemp $=379$ and Uemp $=344$, respectively, were revealed;

- insignificant differences between the use of such a strategy as the search for social support of students of experimental and control groups Uemp $=398$ were revealed.

As the preliminary results of the study show, the multidirectional semantic position of the participants of the educational process is of particular importance for the development of regulatory competence. In this case, the participants of didactic interaction enter into a destructive interaction based on the opposite direction of goal-setting; different models of planning professional and educational outcomes; different measure and quality of readiness for the correction of professional and educational activities; subjective assessment of the motivational value attitude of the participants of the educational process to achieve the possible result for each participant; the ability to self-regulatory manifestation in professional and educational action.

In the course of studying the developed subject for the development of regulatory competence on the basis of codirectional semantic professionally significant didactic interaction, the technique of situational-task modeling, consisting of a set of techniques, which include: facilitation, counseling, the implementation of the position of moderator, tutor and coach, work in micro-groups (small groups), brainstorming, aquarium, cases.[3]

Qualitative characteristics of the co-directional semantic professionally significant didactic interaction included the following set of parameters: valuable emotionally significant image of personally possible professional action (motivation to achieve the goal; emotional dynamism of educational activity); intellectual and cognitive search and realization of personal meanings of future professional action (conscious self-organization of educational activity; semantic professionally significant correction of educational action); active self-organization masters in educational environment (the relationship motivation of educational activity and the mastery of the master's integrative set of personality characteristics that form the basis for the development of regulatory competence; professional sense of training activities).

The resulting component of the considered interaction was the technology of "educational semantic Elevator" implemented by students as a trajectory of individual and personal self-development in the conditions of psychological and pedagogical support from teachers and psychologists. In the context of the development of regulatory competence, students in the course of semantic co-directional interaction with teachers moved along the following trajectory of selfdevelopment: from the first year (awareness of professionally significant meaning of educational activities-cognitive component; formation of professional competencies-communicative and behavioral component; motivation and 
awareness of the personal importance of the future profession-emotional component) to the second (mastery of psychological and pedagogical methods of self-development; interactive professionally significant didactic position).

A special role was played by classes on the development of critical thinking as a basis for the quality of regulatory competence development in the process of semantic interaction between teachers and students, assuming the presence of skills to distinguish between factual information and evaluative judgments; facts and assumptions; to detect factual and logical errors in reasoning. In addition, a set of role-playing and business games was used.

The effectiveness of the work was evaluated according to the following criteria:

- readiness to transform the didactic goal and task into professionally significant ones;

- mastering the acmeological model of correlation of the content of the chosen activity and personal potential;

- readiness to independently implement the skills of professionally significant self-organization in the educational action;

- readiness for constructive interaction;

- readiness for self-regulation as a conscious technology for managing emotional States, behavior and activities;

- possession of skills of procedural, resultant and prognostic self-control.

Conclusions: the Study of regulatory competence as a factor of semantic co-directed interaction of teachers and graduate students of the University suggests the existence of interdependence of development of readiness of the participants of educational process of the University samoregulyatsiya to support the personal development trajectory of the editing process of conscious semantic changes position at different stages professionally directed didactic interaction between teachers, employers and students.

\section{Literature}

1. Abakumova, I. V. sense Formation in the educational process [Text]: dis. ... doctor of psychology. Sciences: 19.00.01, 19.00.07 / I. V. Abakumova. - Rostov-on-don, 2003. - 440 PP.

2.Asmolov, A. G. Driving forces and conditions of personality development. Psychology of personality in the works of domestic psychologists. Reader. Text. / A. G. Asmolov. SPb.: Peter, 2000. - 451s.

3.M. H. Baibayeva, P. S. urazbayeva Psychological features of interactive teaching methods [Text] / / Innovative pedagogical technologies: materials of the II international conference. science. Conf. (Kazan, may 2015). - Kazan: Buk, 2015. Pp. 2-4. - URL https://moluch.ru/conf/ped/archive/150/8038/

4.Bondarevskaya, E. V. Pedagogy: personality in humanistic theories and systems of education [Text]: Studies. manual for students. environments'. and more. PED. studies'. institutions, students of IPK and FPK / E. V. Bondarevskaya, S. V. Kulnevich ; Under the General editorship of E. V. Bondarevskaya. - Rostov-on-Don : Creative center "Teacher", 1999. $-560 \mathrm{PP}$.

5.Gershunsky, B. S. Philosophy of education for the XXI century: in search of practice-oriented educational concepts Text. / B. S. Gershunsky. Moscow: Humanist, 1998. 93c.

6.Derkach, A. A. Acmeology: ways to reach the heights of professionalism Text. / A. A. Derkach, N. V. Kuzmina. Moscow: RAU, 1993. 32S.

7.Konopkin, O. A. General ability to self-regulation as a factor of subjective development / / Questions of psychology. 2004. - No. 2. Pp. 128-135.

8.Leontiev, D. A. Psychology of meaning: nature, structure and dynamics of semantic reality [Text] / D. A. Leontiev. 2nd, ISPR. ed. - M.: Sense, 2003.

9.Mehrabian, A. Nonverbal Communication. Chicago, IL: Aldine-Atherton, 1972. 
10.Morosanova V. I. self-Regulation and human individuality [ Text] / V. I. Morosanova. - Moscow : Nauka, 2010. $520 \mathrm{PP}$. 